\title{
Perceptions Towards Evidence Based Medicine and Implementation Obstacles at Primary Care Clinics, King Fahd Armed Forces Hospital, Jeddah City, Saudi Arabia, 2013
}

\author{
Nayef A. Aljohani', Noha A. Dashash ${ }^{2}$ \\ ${ }^{1}$ Family Medicine Department, King Fahd Armed Forces hospital, Jeddah, Saudi Arabia. \\ 2Joint Program of Family and Community Medicine, Jeddah, Saudi Arabia.
}

\begin{abstract}
Objectives: This study was conducted in the Military hospital primary care clinics to determine the perceptions and attitude, as well as to identify obstacles towards practicing Evidence Based Medicine (EBM) among physicians.

Methods: A cross-sectional study using a previously validated self-administered (electronic) questionnaire was conducted.

Results: Out of the 120 primary health care physicians invited to participate in the study, 113 responded, giving a response rate of $94.2 \%$. Fifty two percent of the responders were males and $54 \%$ were Saudi. Qualifications of participants included MBBS degree (69\%) and Board or equivalent degree (14.2\%). Mean rating score (scale 1 to 10) of physicians' attitude towards the current promotion of EBM was 8.01. Family medicine consultants and physicians previously attending EBM courses showed significant positive attitude towards EBM. Lack of personal time (84.1\%), availability and access to information (77.9\%) were the main reported barriers against practicing EBM.
\end{abstract}

\section{INTRODUCTION}

Improvement of patient care in primary care by the identification and promotion of practices with a high quality and safety standards; preventing ineffective or harmful interventions, decreasing errors and reducing cost, are the main reasons behind practicing evidence based medicine (EBM). Furthermore, practicing EBM sorts clinicians who able to access literature according their needs, criticizing it and integrating the best scientific evidence, ensuring advancement of knowledge into their own practice, making them self-directed learners. ${ }^{1,2}$

The term EBM has been defined by Sackett et al as "the conscientious, explicit, and judicious use of current best evidence in making decisions about the care of individual patients." ${ }^{3}$ Its practical meaning is the integration of the best research evidence with clinical expertise and patient values. ${ }^{4}$

Most physicians believe in EBM and want to practice in an evidence-based way. This no longer requires evaluating original research. Instead, it means finding good secondary sources that summarize the literature and give you useful, actionable bottom line synopses; based on the evidence. ${ }^{5}$

Over the past 20 years, EBM has made a difference in all more critical in our thinking about the efficacy and safety of
Conclusion: Primary health care physicians in clinics of KFAFH, Jeddah showed a welcoming attitude towards EBM.

Keywords: Attitude, Evidence based Medicine, Primary care, Physicians.

\section{*Correspondence to:}

Nayef A. Aljohani, SBFM, ABFM

Senior registrar

Family Medicine department,

King Fahd Armed Forces hospital, Jeddah, Saudi Arabia.

\section{Article History:}

Received: 13-08-2016, Revised: 16-08-2016, Accepted: 19-08-2016

\begin{tabular}{|l|c|}
\hline \multicolumn{2}{|c|}{ Access this article online } \\
\hline Website: & \\
www.jmm.com & \\
\hline DOl: & \\
10.21276/jmrp.2016.2.5.004 & \\
\hline
\end{tabular}

interventions. This is evident in the higher standards of our spoken and written work, formal and informal, and in our approach to the subject. 6

Systematic reviews and meta-analyses are of the greatest achievements of EBM, methods by which researchers identify multiple studies on a topic, separate the best ones and then critically analyze them to come up with a summary of the best available evidence. ${ }^{7}$ Flaherty said "In the last few years, we've seen an explosion in the publication of systematic reviews and meta-analyses on useful and practical topics that just weren't looked at previously", "Physicians now have at their disposal a lot of the work already done for them."

Ely and colleagues studied how often family physicians faced clinical questions in their practices and what they did to resolve their uncertainty. The researchers found that clinical questions arose 3.2 times for every 10 patients seen, but physicians did not seek an answer 64 percent of the time. "Most clinical questions don't get answered, and most of the time that's because the physician doesn't pursue an answer. If the physician does pursue an answer, then about 80 percent of the time they'll get a reasonable one, according to our research." ${ }^{5}$ 
Physicians spent less than two minutes seeking an answer to a question. The two most common sources were: fellow physicians and other individuals or textbooks. ${ }^{7}$

"Most physicians depend on relatively low-quality sources of information," says Flaherty. "Traditional medical journal Articles that describe randomized controlled trials may seem credible, but they provide relatively low-quality information when you compare them to what a systematic review on the same topic can provide. Physicians will often read a journal article and then base decisions on that when in fact it's only a tiny part of the picture..$^{7,8}$

In 1999 a study was carried out in the Riyadh Region, Kingdom of Saudi Arabia (KSA), by Al-Ansary and Khoja reported that primary health care physicians have a welcoming attitude to EBM. ${ }^{9}$ In 2007, a study has conducted by Al-Gelban and his colleagues in Aseer, KSA, showed that the main obstacles to the practice of EBM practice were "lack of facilities" followed by "lack of time", while the barrier least mentioned was the "lack of interest". ${ }^{10}$ However, we do not know about the Perceptions of primary care physicians in KFAFH, Jeddah, towards EBM and the obstacles into its implementation. Hence, this study was conducted to evaluate their attitudes and major obstacles against practicing EBM.

\section{SUBJECTS AND METHODS}

A cross sectional study; using a questionnaire adapted from McColl et al. ${ }^{11}$ Using a previously published questionnaire was thought to add strength to the study because it has already been tested and because it would allow for an international comparison to be drawn.

It was conducted in primary care clinics at King Fahd Armed Forces hospital (KFAFH), in Jeddah, Saudi Arabia. Jeddah is a Saudi city located in the middle of the Eastern coast of the Red Sea known as the 'Bride of the Red Sea' and is considered the economic and tourism capital of the country. Its population is estimated around 3.4 million and it is the second largest city after Riyadh. ${ }^{12}$ There are seven satellite clinics associated with the KFAFH. These are the Royal Palace, Prince Sultan Palace, Royal Saudi Airforce, Air Defence Institute, Ground Forces, Naval Base and Al Quadimah clinic.

Primary care clinics have two sections, the male section and the female section, each section has its own reception, registry system and working hours. The working hours in the male section start from 7:30Am - 4:00 PM, then from 4:00 Pm - 12:00 Am. At a.m. there are 10 clinics and 8 clinics at p.m. The working hours in the female section start from 7:30Am - 3:00 PM then from 3:00 Pm - 9:00 Pm. At a.m. there are 14 clinics and 9 clinics at p.m. Estimated number of patients attending primary care center in the morning shift in both sections is about 900-1000 patients. In the evening shift is around 400-500 patients. These clinics provide primary care services to members of the Saudi Arabian Armed Forces and their dependents. Data gathering started at first of May 2013 for a period of 6 months. All primary care physicians working in primary care clinics in KFAFH in Jeddah, regardless of their qualification were invited to participate in study. These were a total of 120 physicians.

A self-administered questionnaire was designed and used in an electronic format, using survey monkey. Questionnaire consisted of four parts: Questionnaire regarding personal, medical practice, questionnaire regarding the attitude toward evidence based medicine, and questionnaire about obstacles against practicing evidence based medicine.

Physicians' responses to 7 questions regarding their attitude towards EBM resources on scales ranged between 1 and 10 were computed in a way that the highest the score, the positive the attitude towards EBM. Thus, the total score ranged between 7 and 70.

A written permission from Joint Program of Family and Community Medicine, Jeddah was obtained before conduction of the research as well as ethical approval from the research ethics committee of KFAFH was obtained. An informed consent was obtained from all participants.

Data analysis was conducted using SPSS software version 20. Continuous variables were presented as mean, median, standard deviation (SD) and interquartile range while categorical variables were presented as frequency and percentage. Student's t-test was utilized to compare two independent quantitative variables and ANOVA test was applied to compare more than two independent quantitative variables. Significance was determined at $p$ value $\leq 0.05$

Table 1: Personal details of the primary care physicians, KFAFH, Jeddah ( $n=113)$.

\begin{tabular}{|c|c|c|}
\hline Personal details & Frequency & Percentage \\
\hline \multicolumn{3}{|l|}{ Gender } \\
\hline Male & 59 & 52.2 \\
\hline Female & 54 & 47.8 \\
\hline \multicolumn{3}{|l|}{ Nationality } \\
\hline Saudi & 61 & 54.0 \\
\hline Non-Saudi & 52 & 46.0 \\
\hline \multicolumn{3}{|l|}{ Medical qualification } \\
\hline MBBS only & 78 & 69.0 \\
\hline Diploma/master & 16 & 16.8 \\
\hline Board/equivalent & 19 & 14.2 \\
\hline \multicolumn{3}{|l|}{ Current job } \\
\hline Intern & 7 & 6.2 \\
\hline Family medicine resident & 28 & 24.8 \\
\hline Family medicine registrar & 12 & 10.6 \\
\hline Family medicine consultant & 5 & 4.4 \\
\hline General practitioner & 48 & 42.5 \\
\hline Others & 13 & 11.5 \\
\hline \multicolumn{3}{|l|}{$\begin{array}{l}\text { Experience of practicing } \\
\text { medicine }\end{array}$} \\
\hline$<2$ & 21 & 18.6 \\
\hline $3-5$ & 29 & 25.7 \\
\hline $6-10$ & 41 & 36.3 \\
\hline $11-20$ & 17 & 15.0 \\
\hline$>20$ & 5 & 4.4 \\
\hline \multicolumn{3}{|l|}{ Place of the clinic } \\
\hline FM clinics & 77 & 68.1 \\
\hline Others & 36 & 31.9 \\
\hline
\end{tabular}


Table 2: Attitude towards EBM among primary healthcare physicians, KFAFH, Jeddah

How would you describe your attitude towards the
current promotion of evidence-based medicine?

- How would you describe the attitude of most of your colleagues towards evidence-based medicine?

\section{- How useful are Research findings in your day to day} management of patients?

- What percentage of your clinical practice do you feel is currently evidence-based?

- "Practicing evidence-based medicine improves patient care"

\section{- Evidence-based medicine is of limited value"}

- The adoption of EBM, however worthwhile as an ideal, places another demand on already overloaded physicians"

Range

Mean $\pm S D$

$8.01 \pm 2.17$

1-10

Not welcoming- Extremely

welcoming

1-10

$6.89 \pm 2.13$

Not welcoming- Extremely welcoming

1-10

$7.42 \pm 2.14$

Useless- Extremely

useful

10-90

$65.49 \pm 18.99$

1-10

$8.67 \pm 1.92$

9

Strongly

Disagree- Strongly agree

$$
\text { 1-10 }
$$

$2.48 \pm 2.10$

Strongly

Disagree- Strongly agree

$$
1-10
$$

Disagree- Strongly agree

\section{RESULTS}

Out of 120 primary health care physicians invited to participate in the study, 113 of them responded giving a response rate of $94.16 \%$. As shown in table 1 , slightly more than half of the participants were males $(52.2 \%)$ and Saudi $(54.0 \%)$. one-third of them $(31 \%)$ had higher degree with $14.2 \%$ having Board or equivalent degree. $24.6 \%$ continuing their family medicine residency training whereas $42.5 \%$ were general practitioners. Almost a third of them (36.3\%) had an experience ranged between 6 and 10 years in practicing medicine.

As illustrated in table 2, physicians were asked to rate their attitude towards the current promotion of evidence-based medicine on a scale ranged between 1 (not welcoming) to 10 (extremely welcoming). A mean score of $8.01 \pm 2.17$ has been obtained. When they were asked to describe the attitude of most of their colleagues towards evidence-based medicine on a scale ranged between 1 (not welcoming) to 10 (extremely welcoming). A mean score of $6.89 \pm 2.13$ has been obtained. Regarding usefulness of research findings in their day to day management of patients, physicians reported a mean score of $7.42 \pm 2.14$ on a scale ranged between 1 (useless) to 10 (extremely useful). Mean percentage of their clinical practice is currently evidence-based was $65.49 \pm 18.99$.

When physicians were asked to rate their attitude towards the statement that practicing evidence-based medicine improves patient care, on a scale ranged between 1 (strongly disagree) to 10 (strongly agree), a mean score of $8.67 \pm 1.92$ has been reported. While when they were asked to rate their attitude towards the statement that Evidence-based medicine is of limited value, on a scale ranged between 1 (strongly disagree) to 10 (strongly agree), a mean score of $2.48 \pm 2.10$ has been reported. In addition, when they were asked to rate their attitude towards the statement that The adoption of EBM, however worthwhile as an ideal, places another demand on already overloaded physicians, on a scale ranged between 1 (strongly disagree) to 10 (strongly agree), a mean score of $4.96 \pm 2.39$ has been reported.

Table 4 shows that non-Saudi physicians reported more positive attitude towards EBM compared to Saudi physicians (mean scores were $54.10 \pm 9.93$ and $50.43 \pm 9.99$, respectively), $p=0.053$. Physicians that had board degree or equivalent expressed more positive attitude than those holding MBBS or diploma/master degrees (mean scores were $56.63 \pm 6.63,51.24 \pm 11.05$ and $51 \pm 7$, respectively). However, this difference was not statistically significant. The highest attitude towards EBM score was reported among family medicine consultants (mean score was $58.4 \pm 5.5$ ) while the lowest score was reported among other titles (man score was $46.69 \pm 10.31$ ). The difference was statistically significant, $\mathrm{p}=0.029$.

Although the physicians working in hospital based clinics showed more positive attitude towards EBM than other clinics (score was $53.31 \pm 9.45$ versus $49.56 \pm 11.04$ ), this difference was not statistically significant $(\mathrm{p}=0.056)$.

The attitude towards EBM score was statistically significantly higher among physicians who attended a course related to EBM than those who did not attend such course (mean attitude scores were54.67 \pm 8.69 versus $44.36 \pm 10.2), p<0.001$. the attitude towards EBM score was statistically significantly higher among physicians who received formal training in search strategy than those who did receive such training (mean attitude scores were $55.73 \pm 7.97$ versus $46.23 \pm 10.47$ ), $p<0.001$. the attitude towards EBM score was statistically significantly higher among physicians who received formal training in critical appraisal than those who did receive such training (mean attitude scores were $54.81 \pm 9.07$ versus $50.80 \pm 10.34$ ), $p=0.047$. 
Table 3: Factors associated with attitude towards EBM among primary health care physicians.

\begin{tabular}{|c|c|c|c|}
\hline & \multicolumn{2}{|c|}{ Physicians attitude towards EBM score $(7-70)$} & \multirow[t]{2}{*}{ p-value } \\
\hline & Mean & SD & \\
\hline \multicolumn{4}{|l|}{ Gender } \\
\hline Males $(n=59)$ & 52.12 & 9.81 & $0.997^{*}$ \\
\hline Females $(n=54)$ & 52.11 & 10.47 & \\
\hline \multicolumn{4}{|l|}{ Nationality } \\
\hline Saudi $(n=61)$ & 50.43 & 9.99 & $0.053^{*}$ \\
\hline Non-Saudi $(n=52)$ & 54.10 & 9.93 & \\
\hline \multicolumn{4}{|l|}{ Medical qualification } \\
\hline MBBS $(n=78)$ & 51.24 & 11.05 & $0.100^{\star *}$ \\
\hline Diploma/master $(n=16)$ & 51.0 & 7.0 & \\
\hline Board/equivalent $(n=19)$ & 56.63 & 6.63 & \\
\hline \multicolumn{4}{|l|}{ Current job } \\
\hline Intern $(n=7)$ & 52.71 & 10.76 & $0.029^{* *}$ \\
\hline Family medicine resident $(\mathrm{n}=28)$ & 48.71 & 10.11 & \\
\hline Family medicine registrar $(n=12)$ & 56.08 & 8.82 & \\
\hline Family medicine consultant $(n=5)$ & 58.40 & 5.50 & \\
\hline General practitioner $(n=48)$ & 53.83 & 9.74 & \\
\hline Others $(n=13)$ & 46.69 & 10.31 & \\
\hline \multicolumn{4}{|l|}{ Place of the clinic } \\
\hline Hospital based $(n=77)$ & 53.31 & 9.45 & $0.083^{*}$ \\
\hline Others $(n=36)$ & 49.56 & 11.04 & \\
\hline \multicolumn{4}{|l|}{ Experience of practicing medicine (years) } \\
\hline$\leq 2(n=21)$ & 50.29 & 9.34 & $0.234^{* *}$ \\
\hline $3-5(n=29)$ & 49.41 & 10.44 & \\
\hline $6-10(n=41)$ & 53.71 & 9.50 & \\
\hline $11-20(n=17)$ & 55.35 & 10.56 & \\
\hline$>20(n=5)$ & 51.40 & 12.60 & \\
\hline \multicolumn{4}{|l|}{$\begin{array}{l}\text { Attending a course related to evidence based } \\
\text { medicine }\end{array}$} \\
\hline Yes $(n=85)$ & 54.67 & 8.69 & $<0.001^{*}$ \\
\hline No $(n=28)$ & 44.36 & 10.20 & \\
\hline \multicolumn{4}{|l|}{ Receiving formal training in search strategy } \\
\hline Yes $(n=70)$ & 55.73 & 7.97 & $<0.001^{*}$ \\
\hline No $(n=43)$ & 46.23 & 10.47 & \\
\hline \multicolumn{4}{|l|}{ Receiving formal training in critical appraisal } \\
\hline Yes $(n=37)$ & 54.81 & 9.07 & $0.047^{*}$ \\
\hline No $(76)$ & 50.80 & 10.34 & \\
\hline \multicolumn{4}{|l|}{${ }^{*}$ Student's t-test } \\
\hline Methods & $\begin{array}{c}\text { Method you are using } \\
n(\%)\end{array}$ & $\begin{array}{c}\text { Method you are interested } \\
\text { to use in future } \\
\mathrm{n}(\%)\end{array}$ & $\begin{array}{c}\text { Most appropriate } \\
\text { method in practice } \\
\mathrm{n}(\%)\end{array}$ \\
\hline $\begin{array}{l}\text { Learning the skills of evidence based } \\
\text { medicine }\end{array}$ & $32(28.3)$ & $31(27.4)$ & $19(16.8)$ \\
\hline \multirow{2}{*}{$\begin{array}{l}\text { - Seeking and applying evidence based } \\
\text { summaries } \\
\text { - Using evidence based practice } \\
\text { guidelines or protocols developed by } \\
\text { colleagues }\end{array}$} & $81(71.7)$ & $76(67.3)$ & $36(31.9)$ \\
\hline & $77(68.1)$ & $69(61.1)$ & $58(51.3)$ \\
\hline
\end{tabular}


As shown in table 4, seeking and applying evidence based summaries was used by $71.7 \%$ of the physicians whereas methods of using evidence based practice guidelines or protocols developed by colleagues and learning the skills of evidence-based medicine were used by $68.1 \%$ and $28.3 \%$ of physicians, respectively.

Among more than half of the physicians $(51.3 \%)$, the most appropriate method in practice was the method of using evidence based practice guidelines or protocols developed by colleagues. Figure 1 shows that the commonest reported barriers to practicing EBM in general practice from physicians' perspectives were difficulties involving whole practice (87.6\%), lack of personal time $(84.1 \%)$, availability and access to information $(77.9 \%)$, patient's ignorance of media $(72.6 \%)$, lack of investment by health authorities (62.8\%) and lack of critical appraisal skills among practitioners.

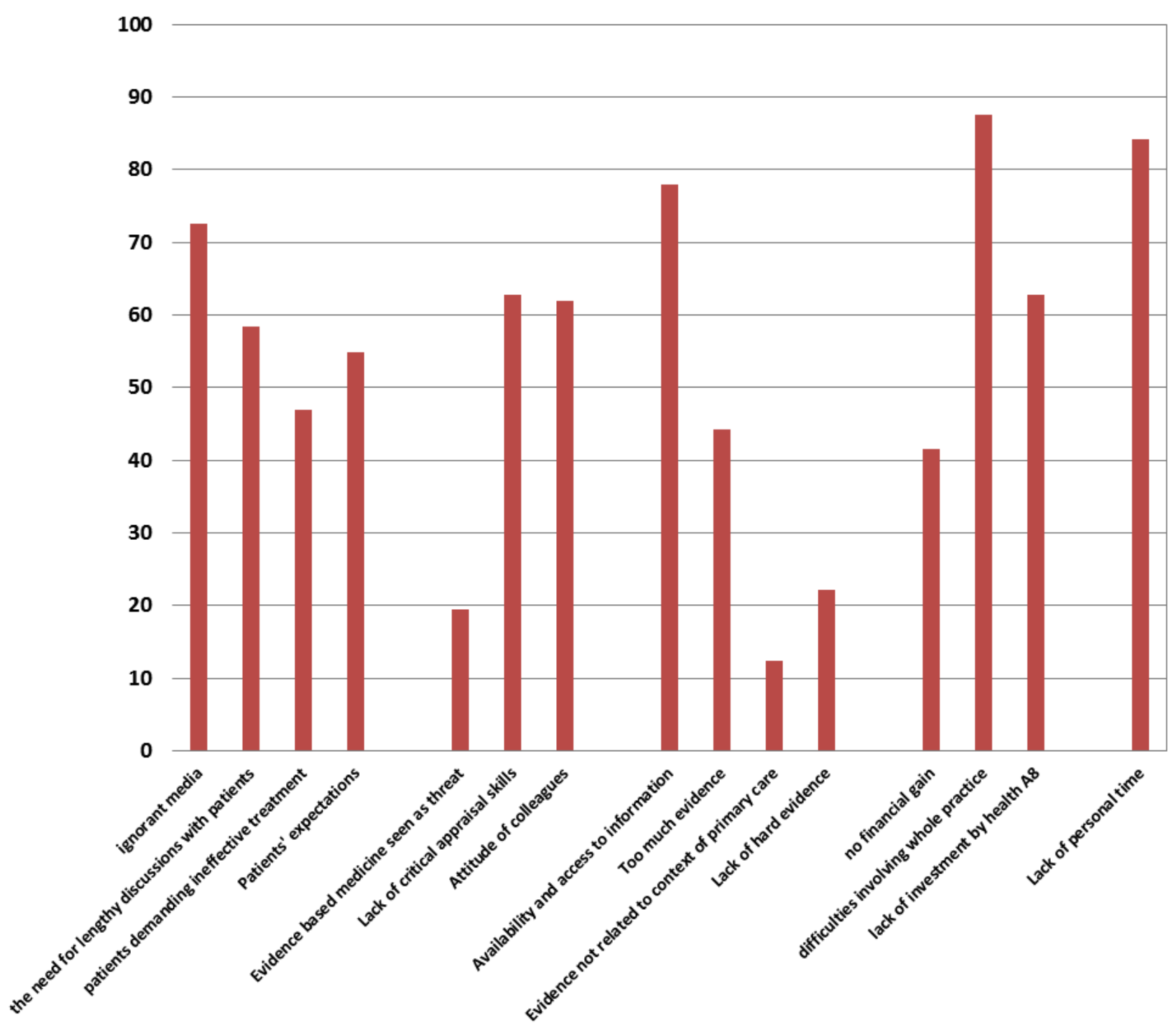

Fig 1: Major barriers to practicing EBM in general practice: primary healthcare physicians' perspectives.

\section{DISCUSSION}

The high response rate $(94.16 \%)$ was in such type of survey and the small percentage of non-responders could have been due to the electronic format of the questionnaire in addition some physicians were on leave. A similar high response rate has been obtained in a study conducted in Aseer region. ${ }^{13}$ There is no information on the non-responders in this study but they are unlikely to be substantially different from the respondents in their evidence-based practice.

The positive attitude of physician'sat KFAFH, was similar to that reported by other author'sboth locally $y^{9,14,15}$ and internationally. . $^{11,16}$ Most of the respondents agreed that practicing evidence based medicine improved patient care and research findings are useful in their day to day management of patients. The median value that describes their attitude towards the current promotion of evidencebased medicine was 9 on a scale ranged between 1 (not welcoming) to 10 (extremely welcoming). Comparable findings have been reported in Taif ${ }^{14}$ and Riyadh, ${ }^{9}$ Saudi Arabia.

Difficulties involving whole practice, lack of personal time, availability and access to information, patient's ignorance of media, lack of investment by health authorities and lack of critical appraisal skills among practitioners were reported to be the main perceived barrier to practicing EBM in general practice. Similar observations were reported by other author's. ${ }^{13,17-19}$ 
Interpretation of our results should be tempered by our study's limitations. It might not be appropriate to generalize it on other types of health care practitioners.

In conclusion, primary health care physicians in clinics of King Fahad Armed forces Hospital, Jeddah showed welcoming attitude towards evidence based medicine. Family medicine consultants, those holding board degrees, attended a course related to EBM, receiving formal training in search strategies or critical appraisal showed more significant positive attitude towards EBM. In the light of the present study's results, we recommended teaching primary health care physicians the basic searching skills and critical appraisal, principles of EBM and how to incorporate these into daily practice is essential though small workshops inside the primary health care centers and regular lectures by doctors who have a board qualification or they had attended evidence based medicine courses and feel more confident in understanding as well as in explaining these terms to others.

\section{REFERENCES}

1. Akobeng AK. Evidence Based Child Health. Principles of evidence based medicine. adc.bmj.comMarch 9, 2013 - Published by group.bmj.com. Arch Dis Child 2005; 90:837-840.

Doi: 10.1136/adc.2005.071761

2. Rajashekhar HB, Kodkany BS, Naik VA, Kotur PF,Goudar SS. Evidence Based Medicineand itsimpact on medical education. Indian J. Anaesth. 2002; 46 (2): 96-103

3. Sackett DL, Rosenberg WMC, Gray JAM, Harnes RB, Richardson WS. Evidence based medicine: what it is and what it isn't. BMJ 1996;312:71-72.

4. Gordon G, Drummond R. User guideto the medical literature: A manual for Evidence-Based clinical practice.United States, American Medical Association 2002.

5. Ely JW, Osheroff JA, Ebell MH, Bergus GR, Levy BT, Chambliss ML, Evans ER. Analysis of questions asked by family doctors regarding patient care. BMJ 1999 Aug 7; 319(7206): 35861

6. Mcquay $\mathrm{H}$. Evidence-Based Medicine: What is the evidence that it has made aaifference? Palliative Medicine 2011 25: 394 Http://Pmj.Sagepub.Com/Content/25/5/394.

Doi: $10.1177 / 0269216310394707$

7. White B. Making Evidence-Based Medicine Doable in Everyday Practice. Fam Pract Manag 2004 Feb; 11(2): 51-58.

8. Flaherty RJ. PPICONS: A simple method for evaluating the clinical literature. Fam Prac Man 2004 May; 11(5): 47-52.

Cited at: www.aafp.org/fpm/20040500/47asim.html

9. Al-Ansary A, Khoja TA. The Place Of Evidence-Based Medicine Among Primary Health Care Physician In Riyadh Region, Saudi Arabia. Fam. Pract 2002 Oct; 19(5):537-542
10. Al-GelbanKS,Al-Khaldi YM, Al-Wadei AM, Mostafa OA. Barriers against application of Evidence-Based Medicine in general hospitals in Aseerregion, Kingdom of Saudi Arabia. J Family Community Med. 2009 Jan-Apr; 16(1): 1-5.

11. McColl A, Smith $H$, White P, Field J. General practitioner's perceptions of the route to Evidence Based Medicine: A questionnaire survey. BMJ1998;316(7128):361-5.

12. Jeddah Municipality, 2013. (Available At: http://www.jeddah.gov.sa/english/ jeddahcity/geographical.php)

13. Khoja TA1, Al-Ansary LA.Attitudes to evidence-based medicine of primary care physicians in Asir region, Saudi Arabia.East Mediterr Health J. 2007 Mar-Apr;13(2):408-19.

14. Al-OmariFK, Al-Asmary SM. Attitude, awareness and practice of Evidence Based Medicine among consultant physicians in Western Region of Saudi Arabia. Saudi Med J. 2006;27(12):188793.

15. Al-Motairy KA, Al-Musa HM. Primary health care physicians' perceptions, attitude and educationalneeds towards' evidence based medicine. Biomedical Research 2013; 24 (2): 257-262

16. Mayer J, Piterman L. The attitudes of Australian general practitionersto Evidence-Based Medicine: A Focus Group Study. FamPract. 1999 Dec;16(6): 627-32.

17. Al-AlmaieSM, Al-Baghli N. Barriers Facing Physicians Practicing Evidence-Based Medicine In Saudi Arabia. J ContinEduc Health Prof. 2004; 24(3):163-70.

18. Jacobson LD, Edwards AGK, Granier SK, Butler CC. Evidence based medicine and general practice. Br J Gen Pract 1997; 47: 449-452.

19. Al-Kubaisi NJ1, Al-Dahnaim LA, Salama RE. Knowledge, attitudes and practices of primary health care physicians towards evidence-based medicine in Doha, Qatar. East Mediterr Health J. 2010 Nov; 16(11):1189-97.

Source of Support: Nil. Conflict of Interest: None Declared.

Copyright: (c) the author(s) and publisher. IJMRP is an official publication of Ibn Sina Academy of Medieval Medicine \& Sciences, registered in 2001 under Indian Trusts Act, 1882.

This is an open access article distributed under the terms of the Creative Commons Attribution Non-commercial License, which permits unrestricted non-commercial use, distribution, and reproduction in any medium, provided the original work is properly cited.

Cite this article as: Nayef A. Aljohani, Noha A. Dashash. Perceptions Towards Evidence Based Medicine and Implementation Obstacles at Primary Care Clinics, King Fahd Armed Forces Hospital, Jeddah City, Saudi Arabia, 2013. Int J Med Res Prof. 2016; 2(5):16-21. 